\title{
Stretch-mediated Activation of Selective MAPK Subtypes and Potentiation of AP-1 Binding in Human Osteoblastic Cells
}

\author{
Fiorenzo A. Peverali, ${ }^{1}$ Efthimia K. Basdra ${ }^{2}$ and Athanasios G. Papavassiliou ${ }^{3}$ \\ ${ }^{1}$ Istituto di Genetica Biochimica ed Evoluzionistica - Consiglio Nazionale delle Ricerche, Pavia, Italy \\ ${ }^{2}$ Poliklinik für Kieferorthopädie, Universität Heidelberg, Heidelberg, Germany \\ ${ }^{3}$ Department of Biochemistry, School of Medicine, University of Patras, Patras, Greece \\ Accepted November 3, 2000
}

\begin{abstract}
Background: It is widely accepted that mechanical loading is necessary to construct the architecture of bone and to maintain bone mass. However, the molecular mechanisms whereby bone cells respond to mechanical stimuli remain elusive. The mitogen-activated protein kinase (MAPK) signaling cascades are known to play a crucial role in the immediate osteoblast response to a variety of bone-active agents. An important component of this response occurs at the transcriptional level and is executed by downstream phosphorylation substrates, most notably, a number of signal-responsive transcription factors. To identify whether the MAPKs are involved in the mechanotransduction process and to determine the effect on downstream transcription factors, we stimulated human periodontal ligament (hPDL) osteoblast-like cells by mechanical stretching by employing an established in vitro model of continuous stretch application.

Materials and Methods: Whole-cell extracts were prepared from cultivated hPDL cells that were exposed to short-term, continuous mechanical stretch. In-gel kinase assays were used to assess their kinase activity towards the immediate-early gene products c-Jun and c-Fos
\end{abstract}

[constituents of the activator protein-1 (AP-1) transcription factor]. Electrophoretic mobility-shift and southwestern experiments utilizing a DNA sequence that contained a previously undefined atypical AP-1-binding site in the promoter of the human liver/bone/kidney alkaline phosphatase (L/B/K ALP) gene (an early marker for osteoblastic differentiation) were employed to evaluate their specific binding capacity.

Results: Selective members of the MAPK family were rapidly induced by stretching, as manifested by their ability to enhance phosphorylation of their cognate substrates c-Jun and, to a lesser extent, c-Fos in the in-gel kinase assay. This induction was accompanied by markedly increased, phospho-c-Jun-containing AP-1-binding activity, as determined by the binding analyses performed with the relevant sequence from the L/B/K ALP promoter.

Conclusions: In as much as AP- 1 is instrumental in regulating genes activated at the onset of osteoblast differentiation, such as the ALP gene, we pose that an interplay of distinct MAPKs targeting AP-1 components may dictate the osteogenic response of hPDL cells to mechanical stimulation.

\section{Introduction}

The periodontal ligament (PDL) is a dense connective tissue situated between the tooth-root cementum and the alveolar bone that anchors the tooth and maintains the structural integrity of these mineralized tissues. It has been regarded as the source of cementoblasts and osteoblasts. Cell kinetic experiments have shown that PDL fibroblasts, the predominant cells of the PDL, comprise a renewal cell system in steady-state and the progenitors can generate multiple types of more differentiated, specialized cells that are involved in the homeostasis of both the ligament and adjacent bone tissue (1). Indeed, PDL

Address correspondence and reprint requests to: Athanasios G. Papavassiliou, M.D., Ph.D., Department of Biochemistry, School of Medicine, University of Patras, GR-26110 Patras, Greece. Phone: ++30 61 996144; Fax: ++3061 996110;

E-mail: papavas@med.upatras.gr fibroblasts have been shown to bear an osteogenic potential (hence osteoblastic fibroblasts) and undergo osteoblastic differentiation or proliferate in culture, depending on various extracellular stimuli (2-8). Due to their anatomical location, cells in the PDL receive mechanical stress by bite force, resulting in cell deformation. The ability of these cells to respond to mechanical load $(1,9)$ suggests that they have a central role in mediating the osseous remodeling that underlies the development, function, and regeneration of the tooth support apparatus in both physiological and clinical settings.

A brief period of load application initiates a complex series of biochemical events in bone cells, resulting in a substantial rise in bone-forming activity $(10,11)$. Considerable work has been done to identify the molecules implicated in mechanical sensing, biochemical coupling, and effector response for this mechano-transduction. Nevertheless, 
the mechanisms underlying these events, as well as their biological role have not been resolved. Shyy and Chien (12) postulated that the integrins constitute a mechano-receptor and that stress fibers are necessary to transmit the applied forces. The integrin family of cell-surface receptors are the principal receptors for extracellular matrix (ECM) proteins and serve as transmembrane bridges between the ECM and actin-containing cytoskeletal structures. Integrinmediated signaling and signal modulation involves the productive engagement of integrins with their ECM ligands, integrin clustering, and the formation of organized complexes between integrins and cytoskeletal proteins (13). The organization of integrinassociated stress fibers and focal adhesions (i.e., complex mixtures of structural and signaling molecules) is governed by members of the Rho family of Ras-related GTPases (13). In addition to their roles in the assembly of actin cytoskeletal structures, Rho family members and cooperating proteins [e.g., focal adhesion kinase (FAK)] can induce a multiple kinase cassette, including elements of the mitogen-activated protein kinase (MAPK) cascades, culminating in activation of transcription factors (14).

The MAPK phosphorylation cascades provide a key link between the membrane-bound receptors that receive environmental cues and changes in the pattern of gene expression. At least three such pathways that activate different MAPK classes have been identified: extracellular signal-regulated kinase (ERK), stress-activated protein kinase/c-Jun Nterminal kinase (SAPK/JNK), and p38 (originally isolated as a hyperosmotic stress-induced kinase) $(15,16)$. Each has varied roles, depending on the cell type and context, that include transmitting stress, growth, differentiative, and apoptotic signals to the nucleus. The best-characterized members of the MAPK superfamily, with regard to transduction of bone-active stimuli, are the ERKs (two major isoforms, p44ERK 1 and p42ERK2) and the JNKs (two major isoforms, p46JNK1 and p54/55JNK2 although alternative splicing may give rise to as many as 10 distinct proteins encoded by three genes) (17-19). These kinases target an overlapping set of transcription factors that lead to the differential activation of rapid response genes, particularly members of the jun and fos family of immediateearly genes (20). C-Jun, together with the Fos family of proteins (c-Fos, FosB, Fral/2), are major components of the AP-1 (activator protein-1) transcription factor, which plays a central role in controlling gene expression early in osteoblast differentiation (2 1-23). The Jun-Jun/Jun-Fos dimeric AP-1 complex (24) interacts with a nucleotide sequence motif known as the 12-O-tetradecanoyl-phorbol13-acetate (TPA)-response element (TRE; consensus sequence TGA [C/G]TCA) (25) located in the promoter region of responsive osteoblastic genes (2123). Related noncanonical TREs also bind AP-1 complexes (26). The binding affinity for a particular
TRE is dependent on the composition of the AP-1 complex (26), which varies as a function of bone-cell proliferation and differentiation (27). ERK/JNK signaling pathways influence AP-1 activity by both increasing the abundance of AP-1 components and stimulating their activity directly via phosphorylation (28).

We previously reported that Rho and other Ras-related GTPases are implicated in the response of human periodontal ligament (hPDL) cells to mechanical stretching in a cell-specific manner (3). These data, combined with the observations that: 1) mechanical stimulation of PDL cells alters ECM protein synthesis (29); 2) ERK MAPK signaling is involved in the stimulation of osteoblastspecific gene expression by ECM/integrin receptor mechanostressing (30,31); and 3) mechanical strain evokes SAPK/JNK activation in other cellular systems $(32,33)$, prompted us to test the hypothesis that MAPKs are triggered by stretching forces of physiological magnitude and that their induction instigates AP- 1 activity that could be relevant to differentiation of hPDL cells. Using an elaborated system of specially designed dishes fitted with a flexible bottom and a simple stretch application device (3), cultured hPDL cells were exposed to short-term continuous mechanical stretch and crude protein extracts were obtained. Their kinase activity against the immediate-early gene products c-Jun and c-Fos, was tested in in-gel kinase assays. TRE-binding capacity was evaluated in binding experiments utilizing a DNA sequence that contained a previously undefined atypical TRE in the promoter of the human L/B/K ALP gene, an early marker for osteoblastic differentiation.

\section{Materials and Methods General}

Cell culture media and reagents were obtained from Gibco/BRL (Eggenstein/Leopoldshafen, Germany); fetal calf serum (FCS) was bought from Biochrom (Berlin, Germany). $\left[\gamma_{-}{ }^{32} \mathrm{P}\right]$ adenosine triphosphate ([ $\gamma{ }_{-}^{32}$ P]ATP; specific activity 5,000 $\left.\mathrm{Ci} / \mathrm{mmol}\right)$ and ${ }^{14} \mathrm{C}$-methylated molecular size protein markers were purchased from Amersham Buchler (Braunschweig, Germany). Oligonucleotides were synthesized by the phosphoramidite method in an Applied Biosystems DNA synthesizer (EMBL, Heidelberg, Germany) and used without further purification. T4 polynucleotide kinase and $10 \times$ buffer for probe labeling were purchased from Boehringer Mannheim Biochemica (Mannheim, Germany). Rabbit polyclonal antibodies to c-Jun, JunB, JunD, c-Fos, FosB, Fral, Fra2, and Spl were purchased from Santa Cruz (Heidelberg, Germany). Detergents were bought from Calbiochem (Bad Soden, Germany). All other chemicals were provided by Sigma Chemie (Deisenhofen, Germany) or Merck (Darmstadt, Germany) and were of the highest available grade. 


\section{Isolation and Culture of Human PDL (hPDL) Cells}

HPDL fibroblasts were obtained from explant cultures of PDL tissues dissected from the roots of healthy teeth extracted for orthodontic treatment purposes (3). The explant was soaked in chick embryo extract, fixed by clotting to culture flasks with chick plasma clots, and cultured in Dulbecco's modified Eagle's medium (DMEM) supplemented with 10\% (volume per volume; v/v) FCS, nonessential amino acids, and antibiotics (100 IU/ml penicillin, $100 \mu \mathrm{g} / \mathrm{ml}$ streptomycin, $0.25 \mu \mathrm{g} / \mathrm{ml}$ amphotericin), henceforth denoted standard media, with media changes every 2 or 3 days. Cultures were maintained at $37^{\circ} \mathrm{C}$ in a $5 \%$ $\mathrm{CO}_{2}$ humidified atmosphere. The outgrowth of fibroblastic cells from the explants started 8-10 days after their initial culture. At confluence, the cells were trypsinized with $0.15 \%$ trypsin $/ 0.5 \mathrm{mM}$ ethylenediaminetetraacetic acid (EDTA), harvested by centrifugation, washed in phosphate-buffered saline (PBS), transferred into $75 \mathrm{~cm}^{2}$ flasks containing the standard media, and cultured until confluency (passage 0 ). The cells were then trypsinized as before and subcultured at $1: 4$ split ratio on Petriperm $^{\mathrm{TM}}$ tissue-culture dishes (Bachofer Germany). Experiments were carried out with cells from the third to sixth passages.

\section{Exposure of Cultured hPDL Cells to Mechanical Stretch}

Approximately $4 \times 10^{5}$ cells were seeded onto 50 mm dishes with a flexible, hydrophilic growth surface (Petriperm ${ }^{\mathrm{TM}}$; Bachofer, Germany) and cultivated, at $37^{\circ} \mathrm{C}$ in standard media, until they reached $\sim \mathbf{8 0} \%$ confluency. Subconfluent hPDL fibroblast cultures were continuously stretched using the stretching apparatus described previously (3). Briefly, this apparatus applies physical force deforming the bottom of the culture dish, to which the hPDL fibroblasts are firmly attached. The bottom of the Petriperm dish can be stretched by placing a template with a convex surface underneath and applying a weight on top of the dish cover, thus forcing the membrane to adapt to the convex surface. The stimulation can be quantitated by calculating the percent expansion of the membrane $(3,34)$. For the experiments presented here, a template was used that produced a $2.5 \%$ increase in surface area (i.e., percentage of stretch $=2.5 \%$ ). This amount of stretching closely resembles the strain forces exerted on PDL cells in vivo (3). In earlier studies that used identical culture dishes and similar stretching forces, minimal cell damage and no evidence of cell detachment were recorded $(3,7)$. Following continuous stretch application for the indicated times, the medium was carefully aspirated and the cells were lysed as described below. Control (unstretched) cultures were incubated under the same conditions for the maximum period of stretch application.

\section{Source of Recombinant c-Jun and c-Fos Proteins}

The full-length c-Jun and c-Fos proteins used for ingel kinase assays (see below) were C- or N-terminally histidine tagged, respectively, and expressed in bacteria from available pET-derived expression vectors. The plasmids were transformed into Escherichia coli BL21 (DE3) and the expressed proteins were purified by nickel-chelate affinity chromatography under denaturing conditions as described $(35,36)$.

\section{In-gel Kinase Assays}

Protein extracts from mechanically stretched (for 7$30 \mathrm{~min}$ ) and control hPDL cell cultures were prepared in sodium dodecyl sulphate (SDS) sample buffer as described (37). In-gel kinase assays were performed by fractionating equal amounts of extract proteins $(50 \mu \mathrm{g})$ onto a routine SDS-10\% polyacrylamide gel, in which recombinant, full-length c-Jun or c-Fos protein $(100 \mu \mathrm{g} / \mathrm{ml})$ were embedded. To remove SDS, the gel was soaked twice for $30 \mathrm{~min}$ in $200 \mathrm{ml} 20 \%$ 2-propanol, $50 \mathrm{mM}$ N-2-hydroxyethylpiperazine- $N^{\prime}$-2-ethane sulfonic acid (HEPES)$\mathrm{NaOH}$ (pH 7.6) and twice for $30 \mathrm{~min}$ in $200 \mathrm{ml}$ buffer A (50 mM HEPES-NaOH, pH 7.6, 5 mM $\beta$-mercaptoethanol). The gel was then incubated for $1 \mathrm{hr}$ in $200 \mathrm{ml} 6 \mathrm{M}$ urea in buffer $\mathrm{A}$ at room temperature, followed by serial, 20-min incubations with $200 \mathrm{ml}$ buffer A containing $0.05 \%$ Tween 20 and 3, 1.5 or $0.75 \mathrm{M}$ urea, respectively, at $4^{\circ} \mathrm{C}$. After five $20-\mathrm{min}$ washes with $200 \mathrm{ml}$ buffer A containing $0.05 \%$ Tween 20, the gel was preincubated for $20 \mathrm{~min}$ at $30^{\circ} \mathrm{C}$ in $30 \mathrm{ml}$ kinase buffer (40 mM HEPES-NaOH, pH 7.6, $20 \mathrm{mM}\left[\mathrm{Na}_{2}\right] \beta$-glycerophosphate, $20 \mathrm{mM}$ $\left[\mathrm{Na}_{2}\right] p$-nitrophenylphosphate, $0.1 \mathrm{mM}$ sodium vanadate, $2 \mathrm{mM}$ dithiothreitol [DTT], $5 \mathrm{mM} \mathrm{MgCl}, 2 \mathrm{mM}$ $\mathrm{MnCl}_{2}$ ) and subsequently incubated for $1 \mathrm{hr}$ in $20 \mathrm{ml}$ kinase buffer containing $50 \mu \mathrm{M}$ ATP, including $5 \mu \mathrm{Ci} / \mathrm{ml}\left[\gamma^{-32} \mathrm{P}\right]$ ATP. Finally, the gel was washed extensively in 5\% trichloroacetic acid (pH 5.7), $1 \%$ sodium pyrophosphate, and 2 mM ATP overnight at room temperature, followed by drying and autoradiography (36).

\section{Electrophoretic Mobility-shift Assays (EMSAs)}

The oligonucleotide sequence used as probe or as competitor was as follows: 5'-GATATGTTGACAGACACAGAG-3' (top strand). This 21-base segment encompasses the atypical TRE (TGACAGA) of the human L/B/K ALP 5'-most promoter (la) with its flanking sequences (38). Equimolar amounts of the above synthetic oligonucleotide and its complementary (bottom) strand were end-labeled with $\left[\gamma-{ }^{32} \mathrm{P}\right]$ ATP by T4 polynucleotide kinase under standard conditions, annealed, and the double-stranded probe was gel-purified on a $20 \%$ native polyacrylamide gel (39). Crude whole-cell extracts from mechanically stretched (for 15-30 min) and control hPDL cultures were prepared as follows. Cells were 
washed with ice-cold PBS, harvested by scraping and centrifugation, and cell pellets were homogenized by resuspension in lysis buffer $(20 \mathrm{mM}$ HEPES-NaOH, pH 7.5, $20 \%$ glycerol, $0.38 \mathrm{M} \mathrm{NaCl}, 2 \mathrm{mM} \mathrm{MgCl}_{2}$, $10 \mathrm{mM}$ sodium fluoride, $10 \mathrm{mM}\left[\mathrm{Na}_{2}\right] \beta$-glycerophosphate, $10 \mathrm{mM}\left[\mathrm{Na}_{2}\right] p$-nitrophenylphosphate, $0.1 \mathrm{mM}$ sodium vanadate, $2 \mathrm{mM}$ phenylmethylsulfonylfluoride (PMSF), $5 \mu \mathrm{g} / \mathrm{ml}$ aprotinin, $2 \mu \mathrm{g} / \mathrm{ml}$ pepstatin, $2 \mu \mathrm{g} / \mathrm{ml}$ leupeptin, $2 \mathrm{mM}$ DTT), and brief sonication. The extract was centrifuged at 12,000 rpm for $5 \mathrm{~min}$ at $4^{\circ} \mathrm{C}$ to remove particulate material and the supernatants were snap-frozen and stored at $-70^{\circ} \mathrm{C}$ prior to use. Equivalent amounts of cell extracts $(5-10 \mu \mathrm{g})$ were mixed with $\sim 5 \mathrm{ng}$ of radiolabeled probe $(\sim 50,000 \mathrm{cpm})$ in a total reaction volume of $20 \mu \mathrm{l}$ containing $250 \mathrm{ng}$ sonicated salmon sperm DNA as nonspecific competitor, $5 \%$ glycerol, $1 \%$ Nonidet P-40, and $2 \mathrm{mM}$ DTT. Following incubation at room temperature for $30 \mathrm{~min}$, DNA-protein complexes were resolved on $5 \%$ native polyacrylamide gels (acrylamide:bisacrylamide, 38:1). Electrophoresis was carried out in $0.4 \times$ Tris/borate/EDTA buffer (TBE; $1 \times$ TBE $=90 \mathrm{mM}$ Tris $/ 64.6 \mathrm{mM}$ boric acid/2.5 mM EDTA, pH 8.0) at $125 \mathrm{~V}$ at room temperature (35). Gels were dried and exposed to X-ray film overnight at $-80^{\circ} \mathrm{C}$ with an intensifying screen. Cold competition with molar excess of unlabeled oligonucleotides was accomplished by simultaneous addition with the radiolabeled probe. For antibody competition or "supershift" assays, the antiserum [0.75 $\mu \mathrm{l}$ of polyclonal anti-Jun/Fos/Spl anti-rabbit antibody or preimmune immunoglobulin $\mathrm{G}(\mathrm{IgG})$ ] was added to the reaction mixture for $30 \mathrm{~min}$ prior to addition of radiolabeled probe or after binding equilibration, respectively.

\section{Southwestern Assay}

Equal amounts of whole-cell lysates $(50 \mu \mathrm{g}$ total protein), prepared as described above from mechanically stretched (for 7-60 min) and control hPDL cultures were mixed with 0.33 volumes of $4 \times$ Laemmli SDS sample buffer and loaded on a SDS-10\% polyacrylamide gel without prior boiling. After electrophoresis, proteins were electroblotted onto nitrocellulose membrane (BA85; Schleicher $\delta$ Schuell, Dassel, Germany) in transfer buffer (20 mM $\mathrm{Na}_{2} \mathrm{HPO}_{4} / \mathrm{NaH}_{2} \mathrm{PO}_{4}, \mathrm{pH}$ 7.0) at $1.15 \mathrm{~A}$ for $\mathrm{l} \mathrm{hr}$ (39). The membrane-bound proteins were renatured under previously established conditions (39) and probed with $\sim 5 \mu \mathrm{g}\left(\sim 5 \times 10^{7} \mathrm{cpm}\right)$ of the same radiolabeled TRE-containing oligonucleotide employed in the EMSAs, in a hybridization bag for $5 \mathrm{hr}$ at $4^{\circ} \mathrm{C}$. Following stringent washing at $4^{\circ} \mathrm{C}$ (39), the membrane sheet was air-dried and autoradiographed.

\section{Results}

Selective MAPK Family Members Are Rapidly Induced in Continuously Stretched hPDL Osteoblastic Cells

HPDL cells derived from explant cultures of healthy PDL tissues were cultivated on a flexible substratum under previously established conditions (3). HPDL cell cultures were subjected to short-term continuous mechanical stretching on a convex template with a weight applied on top and producing a $\sim 2.5 \%$ degree of stretch (3). To determine if reception of this type of mechanical stretch in hPDL cells is coupled functionally to the MAPK signaling cascades, we pursued in-gel kinase reactions. To this end, recombinant full-length c-Jun or c-Fos proteins (well-characterized in vitro and in vivo substrates of MAPKs) $(24,40)$ were fixed in a SDSpolyacrylamide gel prior to separation of proteins prepared from control and stretched $(7-30 \mathrm{~min})$ hPDL cells. The lysates were electrophoresed on the c-Jun/c-Fos-containing gels, and phosphorylation of the proteins was assayed by soaking the gel with $\left[\gamma-{ }^{32}\right.$ P]ATP after a renaturation step (36). As shown in Figure 1 (left panel), two sets of bands with different thickness and density and apparent molecular masses in the range of well-defined MAPKs (42$55 \mathrm{kDa}$ ) (17) were gradually induced in mechanically stretched hPDL cells and augmented the baseline phosphorylation of c-Jun. The upper two bands (greater intensity) most likely represent different JNK isozymes that are expressed in these cells, with the upmost one (54/55-kDa protein) corresponding to the $M_{r}$ of JNK2 $(18,19)$. Interestingly, no activity of the JNK1 (46-kDa isoform; a poor, compared with JNK2, c-Jun kinase in vitro) $(18,41)$ was revealed in hPDL cells. The lower two bands (44- and 42-kDa proteins) corresponded to the $M_{r}$ of ERK1 and ERK2, respectively (17). There were no distinguishable differences in the activity of the $44-\mathrm{kDa}$
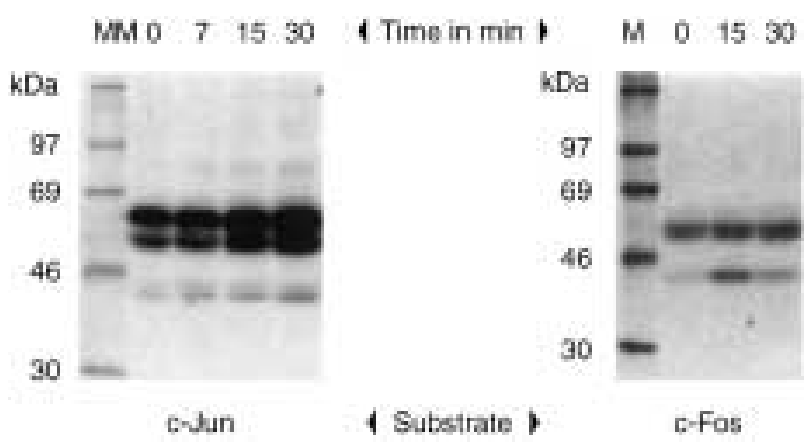

Fig. 1. Continuous mechanical stretching of human periodontal ligament (hPDL) osteoblast-like cells enhances mitogen-activated protein kinase (MAPK) activity. Equivalent amounts of whole-cell lysates obtained from unstimulated (0) or mechanically stretched cells (for the indicated time in min) were subjected to in-gel kinase assays, in which bacterially expressed full-length c-Jun protein (left panel) or c-Fos protein (right panel) served as immobilized substrates in the presence of $\left[\gamma^{32} \mathrm{P}\right]$ ATP and the respective kinase buffer. Kinases present in these cellular extracts that can phosphorylate c-Jun/ c-Fos were identified by autoradiography of the washed and dried sodium dodecyl sulfate (SDS) polyacrylamide gel. Molecular masses of ${ }^{14} \mathrm{C}$-methylated protein standards $(\mathrm{M})$ are indicated. The results are representative of three experiments using two different lysates. 
protein (ERK1) between control and hPDL cells loaded with mechanical stretch. The 42-kDa species (ERK2), however, exhibited a pattern of induction similar to that of JNK2. When c-Fos was used as substrate in the in-gel kinase reaction, two bands in the same region of the gel were noted (Fig. 1, right panel). One of them exhibited negligible alteration in its activation profile in response to mechanical stretch and was not considered further. The 42-kDa band, corresponding to the $M_{r}$ of ERK2 (17), showed a substantial increase in activity after $15 \mathrm{~min}$ of exposure to mechanical stretch that returned to almost basal levels at $30 \mathrm{~min}$. These results indicate that induction of the JNK and ERK MAPK subgroups is an immediate-early event in the response of hPDL cells to continuous mechanical stretch.

\section{Stretch-triggered JNK/ERK Induction Coincides with Increased AP-1-Binding Activity on an Osteoblast-specific Promoter}

Activated JNKs (41-43) and ERKs (44-46) are known to phosphorylate c-Jun on N-terminal residues within its trans-activation domain, enhancing the DNA-binding and transcriptional activity of the molecule $(35,47,48)$. C-Jun forms a homodimer or a hetero-dimer with the Fos family (AP-1 transcription factor) and regulates the expression of many genes that have a TRE (or AP-1-binding site) in their promoter region $(24,29)$. The transcription of the c-jun gene itself is also controlled by AP-1 (28). To assess whether continuous mechanical stretch increases AP-1 protein binding in hPDL cells, we performed a series of EMSAs with a previously uncharacterized, divergent TRE-containing sequence in the $5^{\prime}$-most promoter (la) of the human $\mathrm{L} / \mathrm{B} / \mathrm{K}$ ALP gene (38) and whole-cell extracts prepared from hPDL cells. This promoter (Fig. 2) is preferentially utilized in osteoblastic cells (50), including hPDL cells (5l), and its increased activity is one of the very early events linked to differentiation (52). A 21-bp synthetic oligonucleotide spanning the putative AP-1 motif of the human ALP la promoter was radioactively labeled and incubated with crude protein extracts from hPDL cells loaded with mechanical stretch over a time course (0-30 min). After electrophoretic analysis, a weak protein-DNA complex was detected in extracts from unstretched cells, whose abundance was strikingly increased in extracts from hPDL cells stretched for 15-30 min (Fig. 3). This complex, as well as a faster-migrating species revealed by longer exposure (see below), was competed effectively by an excess of unlabeled probe; whereas, no variation was observed in the complexes when the competitor was a molar excess of either mutant (consensus) AP-1 or an unrelated oligonucleotide (data not shown). Consistently, these complexes were not observed when binding experiments were carried out with extracts incubated in the presence of radiolabeled mutant AP-1 oligonucleotide, also ruling out the involvement of an adjacent putative GATA-binding site (see Fig. 2) in complex formation. Induction of AP-1 binding occurred within $15 \mathrm{~min}$ and remained elevated for up to $3 \mathrm{hr}$. In contrast, DNA binding of transcription factor Spl, as an internal control (several putative binding sites are present in the ALP la promoter region; see Fig. 2), did not vary significantly between nonstretched and stretched samples at any time (not shown). Clearly, continuous mechanical stretch of hPDL osteoblast-like cells leads to a rapid increase in AP-1-binding activity, which parallels that of JNK2 and ERK2 up-regulation.

\section{C-Jun is an AP-1-ALP Promoter Complex Participant}

Next, to better assess the composition of proteins that constituted the protein complexes binding to the ALP la promoter AP-1 sequence, the mobilityshift experiment was repeated using extracts from hPDL cells subjected to mechanical stretching for 15 min (Fig. 4A, B). As demonstrated above, stretching resulted in increased AP-1-binding activity (Fig. $4 \mathrm{~A}, \mathrm{~B}$, lane "control"; the second complex is now visible). Since the c-Jun and c-Fos proteins are the principal components of the AP-1 transcription factor and defined targets of the JNK/ERK pathways (40) (see also, Fig. 1), we incubated the extracts with polyclonal antisera to these proteins, to an AP-1 unrelated transcription factor (Spl), or preimmune IgG. Addition of antibody to c-Jun, but not Spl or IgG, resulted in marked diminution of the protein-DNA bands (Fig. 4A, antibody competition assay) or a "supershifted" (i.e., slower-migrating) complex (Fig. 4B, antibody "supershift" assay), thus indicating that the increased AP-1 binding displayed in extracts from continuously stretched hPDL cells was made up, in part, of c-Jun protein. We were unable to demonstrate participation of c-Fos or any of the Fos-related proteins (FosB, Fral, and Fra2) in the specific AP-1 complexes under these conditions, albeit an epitope-masking effect cannot be excluded. Likewise, antibodies recognizing the other Jun family members (JunB and JunD) had marginal effects on the formation or mobility of the complexes (not shown). Thus, the induction of JNK2 and ERK2 by continuous mechanical stretch triggers the downstream AP-1ALP promoter TRE interaction, an effect that is probably was channeled mainly through c-Jun potentiation.

\section{AP-1-ALP Promoter Complexes Correlate with JNK/ERK-Mediated c-Jun Activation}

To gain further insight into the relationship between JNK/ERK induction and c-Jun activation in the response of hPDL cells to continuous mechanical stretch, we analyzed the DNA-binding potential of c-Jun as governed by its phosphorylation state over a time course following stretch application. To this end, hPDL cells were subjected to mechanical stretch 


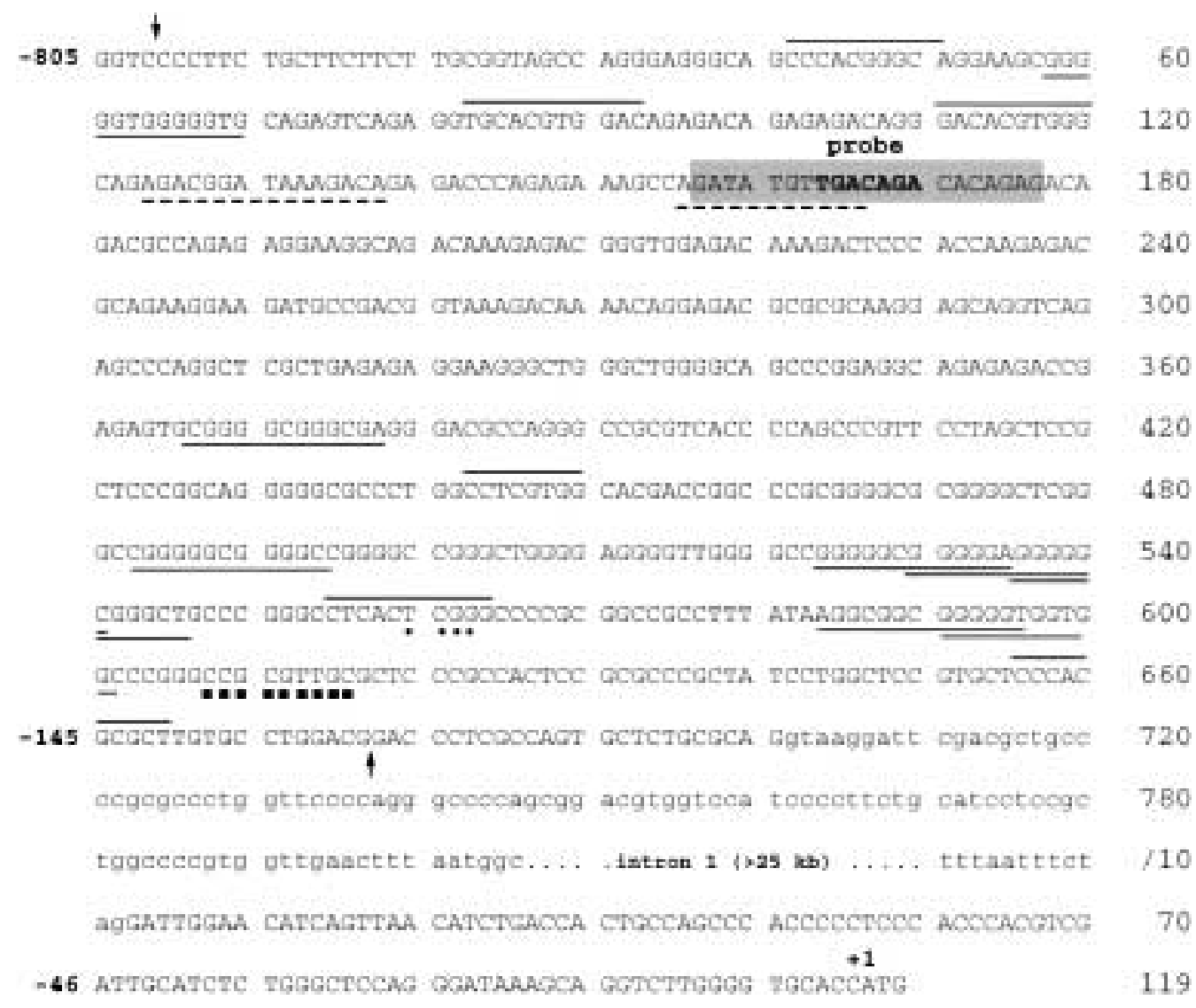

Fig. 2. Nucleotide sequence of the upstream promoter region (exon la) of the human liver/bone/kidney alkaline phosphatase (L/B/K ALP) gene. The numbers on the right side of the nucleotide sequence refer to European Molecular Biology Laboratory (EMBL) accession numbers M24428 (1-806) and M24429 (1-119); whereas, those on the left side are as described (38). The major transcription start sites are shown as black squares. Black dots indicate the minor starts of transcription. The position of the first base of the ATG translation initiation codon (exon 2) is indicated as +1 . The arrows mark the 672-bp Ava II restriction fragment bearing the promoter activity (38). The gray box indicates the nucleotide sequence used as probe for the experiments described in Figs. 3-5. In the boxed region, the atypical 12-O-tetradecanoyl-phorbol-13-acetate (TPA)-response element (TRE) is highlighted in bold. Putative binding sites for the transcription factors Spl; (underlined), upstream stimulatory factor (USF) (overlined), and GATA (broken line) present in the Ava II fragment are also shown. The computer program MatInspector (68) was used to identify the core consensus sequences described. Modified from Weiss et al. (38).

(0-60 min), protein was extracted as before, and a southwestern assay performed that utilized as probe the same AP-1 oligonucleotide employed in the mobility-shift experiments (Fig. 5). The results showed that the DNA-binding capacity of c-Jun was enhanced as early as 7-15 min post-stretch, concomitant with the gradual appearance of slowermigrating, DNA-binding competent species of the protein (most evident at 30-60 min of stretch; Fig. 5). We have previously documented that these lower-mobility species, which can be converted in vitro into the fastest-migrating $39-\mathrm{kDa}$ band by phosphatase digestion, are generated by signalinduced, JNK/ERK-mediated, N-terminal phosphorylations of c-Jun that function as part of a molecular switch eliciting c-Jun DNA-binding activity (35). The immunoreactivity of these bands against a c-Jun polyclonal antibody confirmed a qualitative shift to the retarded, DNA-binding competent species of the protein. These data strongly suggest that the contri- bution of c-Jun to the augmented AP-1-binding activity observed in stretch-stimulated hPDL cells, involves its highly phosphorylated, hence, activated forms. In this regard, we note that differentially phosphorylated forms of c-Jun most likely account for the binding pattern seen in the EMSAs (Fig. 4) (35). Furthermore, this analysis, in correlation with the failure to detect Fos proteins in the AP-1-ALP TRE complexes, implies that a Jun-Jun homodimer, rather than a Jun-Fos heterodimer, serves as the "firing" effector in this mechanical-to-biochemical transmitting process.

\section{Discussion}

Mechanical forces are a fundamental physiological factor for regulating structure and function in many tissues. In bone, mechanical loading stimulates the increase of bone mass and plays an important role in the bone remodeling process $(10,11)$. PDL fibro- 


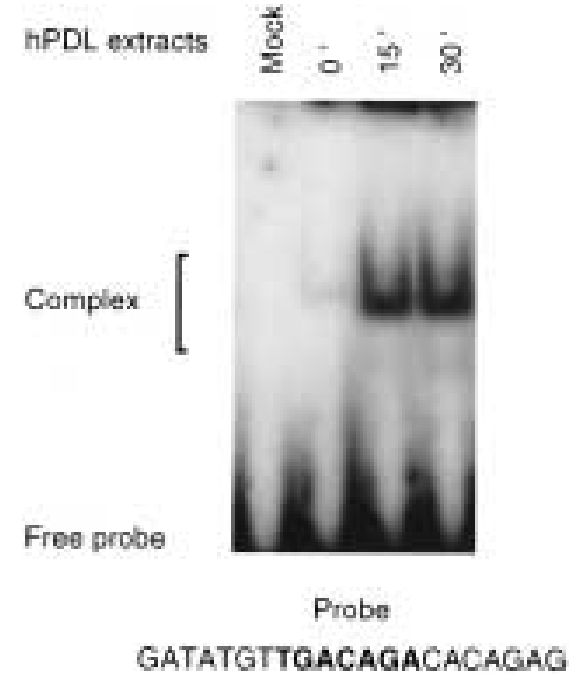

Fig. 3. Mechanical stretching of human periodontal ligament (hPDL) cells stimulates the binding of a complex to the human liver/bone/kidney alkaline phosphatase $(\mathrm{L} / \mathrm{B} / \mathrm{K}$ ALP) 5'-12-O-tetradecanoyl-phorbol-13-acetate (TPA)response element (TRE). Continuous mechanical stretching was applied to hPDL cell cultures for the indicated times in $\min \left(0^{\prime}, 15^{\prime}, 30^{\prime}\right)$ prior to harvesting. Whole-cell extracts were prepared and equal amounts $(5 \mu \mathrm{g})$ analyzed for activator protein-1 (AP-1)-binding activity by an electrophoretic mobility-shift assay (EMSA). After incubation at room temperature for $30 \mathrm{~min}$ with the ${ }^{32} \mathrm{P}$-labeled DNA probe, equilibrated DNA-binding reactions were electrophoresed on a $5 \%$ native polyacrylamide gel. The gel was dried and then subjected to autoradiography. The positions of specific DNA-protein complexes and freely migrating probes are indicated. The sequence of the oligonucleotide used as probe is shown. The atypical TRE is highlighted in bold. "Mock" indicates a reaction mixture incubated in the absence of hPDL cell extracts (negative control).

blasts comprise an osteoblast-like population of cells $(2,4,6)$ that are involved in the normal maintenance, repair, and regeneration of both the ligament and neighboring hard tissues (1). Since the PDL lies between bony tissues and functions as a cushion mitigating mechanical stress, such as occlusal forces, this stress may contribute to the long-lasting homeostatic properties exhibited by PDL cells via modulation of their osteogenic potential. In support of this view, it was reported that mechanical stretch induces cell differentiation in rat osteoblastic cells (53). There is a vast descriptive literature about the effects of various forms of mechanical perturbation on PDL osteoblastic fibroblasts. These analyses reveal that mechanical stress evokes a wide array of changes in second messenger systems and patterns of gene expression in PDL cells. The molecular mechanisms that enable the switch of physical forces to intracellular biochemical signaling events and associated biological outcome are, however, still largely unknown. MAPKs, namely ERKs, SAPKs/ JNKs, and p38, are activated downstream of many different types of receptors that are triggered by a variety of osteoblast-active stimuli (54). Upon acti- vation, these kinases phosphorylate target transcription factors, thereby, modifying their capacity to regulate gene expression. Given this global response to a plethora of factors, MAPKs and their downstream effectors are plausible candidates for mediating the mechano-transcription coupling process in osteoblastic cells.

The present study was undertaken to examine the involvement of the MAPK pathways in the response of hPDL cells to short-term continuous mechanical stretch within physiologic limits. Considering the important role played by the components of the AP-1 transcription factor (Jun and Fos proteins) in the early stages in osteoblast differentiation (21-23), their selective targeting by the stretch-driven MAPK induction and corresponding changes in AP-1 activity towards an early osteoblastic gene promoter were investigated. We demonstrate that application of this type of stretch in hPDL cells rapidly activates selective members of the JNK and ERK MAPK subgroups (i.e., JNK2, as well as a putative JNK isoform, and ERK2), resulting concurrently in a marked increase in APl-binding activity towards a previously undefined divergent TRE in the functional promoter of the human L/B/K ALP gene. Because elevated expression of this ALP isozyme is associated with the onset of the osteoblast phenotype and the formation of new bone (52), we surmise that mechanical stimulation may facilitate the differentiation pathway of hPDL cells (from small fibroblastic precursor-to osteoprogenitor-to bone-forming cells) with c-Jun, and perhaps c-Fos, acting as key effectors of mechano-transduction.

SAPKs/JNKs are affected mainly by environmental stress factors (e.g., UV irradiation, oxidants, hypoxia, heat shock) and less by mitogenic stimuli. Following activation, JNK can bind directly to and phosphorylate c-Jun within its N-terminal transactivation domain, resulting in increased transcriptional activity of target genes. Depending upon the cell type and the context of regulatory inputs that the cell is receiving, JNK activation can lead to proliferation, differentiation, or apoptosis $(19,55)$. Several studies, using various osteoblast-like cell lines, have documented the induction of both JNK 1 and JNK2 by certain cytokines and diverse forms of stress (54). ERKs are regulated by mitogenic factors, neurotrophins, and phorbol esters. Upon their activation, ERKs may phosphorylate and potentiate several transcription factors, including c-Jun, engaged in cell proliferation and differentiation $(15,56)$. A broad range of bone-active agents have been described to induce ERKs in human osteoblast-like cell lines and osteoblastic cells, including various growth factors, estrogen, and fluoride at mitogenic doses (54). Although the ERK cascade appears to be an important component of intracellular signals initiated by many agents having proliferative effects on osteoblastic cells, its in vivo role awaits clarifica- 


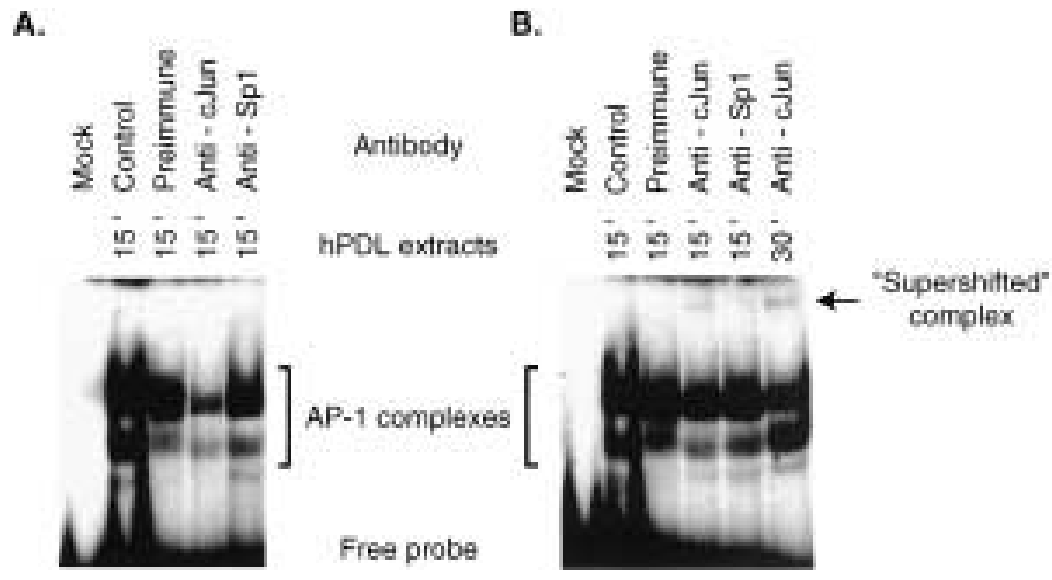

Fig. 4. Identification of c-Jun in the gel-retarded complexes formed by the human liver/bone/kidney alkaline phosphatase (L/B/K ALP) 5'-12-O-tetradecanoyl-phorbol-13-acetate (TPA)-response element (TRE) and extracts from mechanically stretched human periodontal ligament (hPDL) cells. Continuous mechanical stretching was applied to hPDL cell cultures for $15 \mathrm{~min}\left(15^{\prime}\right)$ or $30 \mathrm{~min}\left(30^{\prime}\right)$ prior to harvesting. Whole-cell extracts were prepared and analyzed $(10 \mu \mathrm{g})$ by an electrophoretic mobility-shift assay (EMSA), as in Figure 3. Specific activator protein-1 (AP-1)-binding activity was assayed in (A) antibody competition or (B) "supershift" experiments. Before (B) or after (A) the incubation for 30 min with anti-cJun antibody, anti-Spl antibody, preimmune serum or control buffer, hPDL cell extracts were incubated for 30 min with the ${ }^{32} \mathrm{P}$-labeled DNA probe described in Figure 3. DNA-protein complexes were resolved by electrophoresis on a $5 \%$ native polyacrylamide gel. The positions of AP-1 complexes and freely migrating probes are indicated. Note the reduction of complex formation (A) or the migration of a "supershifted" complex (B; marked by arrow) in the presence of anti-cJun antibody. "Mock" indicates a binding reaction omitting hPDL cell extracts (negative control).

tion. Remarkably, mechanical stress in the form of cyclic strain and shear recently was shown to evoke activation of ERK2 and enhanced, c-Fos-containing AP-1-binding activity in vascular smooth muscle cells, by direct activation of the platelet-derived growth factor (PDGF) receptor (57). The authors conclude that this type of stress may directly perturb the cell surface or alter receptor conformation, thereby subverting signaling pathways normally used by growth factors.

Our in-gel kinase data suggest that simultaneous induction of JNK2 and ERK2 acts to elicit a mechanical stretch response in hPDL cells. The increase in these activities, as well as that of an undefined JNK isoform, exhibit similar apparent kinetics (but not amplitude; Fig. 1), as monitored by the phosphorylation of c-Jun. By contrast, other physical forms of stress, such as osmotic pressure, ultraviolet light, and ionizing radiation, selectively activate the JNK pathway, but not the ERK pathway $(42,58,59)$; whereas, mechanical stimulation exerted by shear stress on vascular endothelial cells preferentially activates JNKs over ERKs (33). In the latter study, the activation of JNK is correlated with increased c-Jun transcriptional activity and induction of endothelial gene expression (33). Thus, while ERKs are less effective kinases of c-Jun in vitro compared with JNKs (41) (evident also in Fig. 1), phosphorylation of c-Jun by ERK2 appears to be able to mediate stretch responses in vivo, at least those observed in hPDL osteoblastic cells. Therefore, we argue that mechanical stretch may provoke a synergistic effect at the level of JNK2 and ERK2 activation, and mol- ecules phosphorylated by these kinases, such as c-Jun, are involved in the reprograming of genes specific for osteoblastic phenotypes. This is reminiscent of our previous findings in Drosophila, which indicate that Jun can act as an effector of both JNK and ERK pathways during differentiation processes in this organism $(36,60)$.

Production of type I collagen-containing ECM by an osteoblast precursor is one of the earlier events associated with osteoblast differentiation, followed by sequential expression of L/B/K ALP,

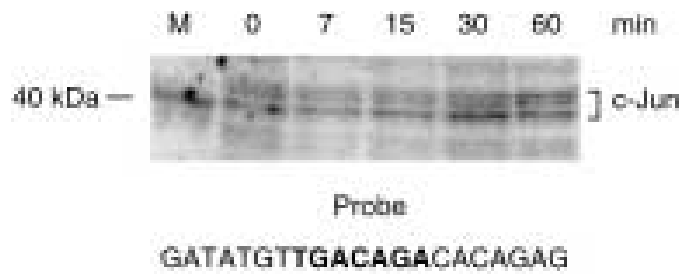

Fig. 5. Southwestern analysis of c-Jun-binding activity to the human liver/bone/kidney alkaline phosphatase $(\mathrm{L} / \mathrm{B} / \mathrm{K}$ ALP) 5'-12-O-tetradecanoyl-phorbol-13-acetate (TPA)response element (TRE) in human periodontal ligament (hPDL) cells upon mechanical stretching. Continuous mechanical stretching was applied to hPDL cell cultures for the indicated time in min prior to harvesting. Whole-cell lysates were prepared and aliquots containing equivalent amounts of protein analyzed by a combined SDS-polyacrylamide gel electrophoresis/protein blotting-renaturation/DNA-binding procedure (southwestern assay). The sequence of the oligonucleotide used as probe is shown (identical to that depicted in Fig. 3). The atypical TRE is highlighted in bold. The molecular mass of the ${ }^{14} \mathrm{C}$-methylated aldolase protein as a size marker is shown (M). 
osteocalcin, osteopontin, and osteonectin. Mineralization of newly formed matrix takes place thereafter. To form bone with structural integrity and physical strength, it appears to be of critical importance to maintain the sequential development of these multiple osteoblastic phenotypes (23). Since commitment to the osteoblast lineage is dependent upon extracellular cues, genes that are activated rapidly by these signals are likely to play a key role early in this process. This rapid induction is accomplished through the signaling-driven modification of proteins that interact specifically with the different promoter elements of these genes. The AP-1 transcription factor is known to be induced rapidly by a wide gamut of stimuli that activate the JNK/ ERK cascades $(28,40,54)$. It exerts its function as a c-Jun homodimer, or a heterodimer comprised of any of the Jun and any of the Fos family proteins that bind to TREs in promoters and modulate the expression of AP-1-responsive genes. AP-1 activity is determined by not only its composition, but also the phosphorylation state of each Jun/Fos heteropartner $(24,40,54)$. In osteoblasts, consensus TREs have been identified in the promoter regions of many osteoblast-specific genes (e.g., type I collagen, osteocalcin, osteopontin) and are implicated in their control (21-23). ALP activity is involved in the process of calcification in various mineralizing tissues, and it is found at much higher levels in the PDL than in other connective tissues $(2,4,6)$. Although numerous transcription factor-binding sequences can be found in the L/B/K ALP la promoter (Fig. 2), there is no mutagenesis or DNAbinding data that support the use of any of these sequences in hPDL cell-specific regulation (52). As noted before, this promoter is functional in hPDL cells (51). Our results reveal that a divergent TRE present in the la promoter is capable of forming specific phospho-c-Jun-containing complexes in extracts from mechanically stretched hPDL cells, implying its function as an early response element conferring stretch-induced ALP transcriptional control. Bearing in mind that divergent TREs can accommodate functional AP-1 complexes (26), and by analogy to this situation, a divergent TRE in the $5^{\prime}$-promoter region of the monocyte chemotactic protein 1 (MCP-1) gene was found to be responsible for its inducibility by shear stress (61). Consistent with our AP-1-binding data on the L/B/K ALP la promoter, hPDL cells exposed to mechanical stress exhibited significant increases in type 1 collagen synthesis (29) and augmented expression of osteocalcin (8), both being prominent determinants of early osteoblastic differentiation. Moreover, in support of the notion that stretch-induced AP-1-binding activity may signal expression of genes linked to progressive maturation of the osteoblast phenotype in hPDL cells, it recently was shown that ALP activity was up-regulated in regenerating hPDL cells (62).
Based on the binding data presented herein (Figs. 3-5), we favor a model in which a JNK2/ ERK2-activated c-Jun homodimer appears to mediate the downstream AP-1-ALP promoter TRE interaction in this stretch-elicited signal transduction pathway. Presumably, the stretch-induced activation of JNK2 and ERK2 leads to phosphorylation of preexisting, latent c-Jun, and the resultant potent cJun-c-Jun homodimer activates the ALP gene by interacting with the divergent TRE on its promoter. In concert with this, mechano-induction of osteopontin expression in embryonic chick osteoblasts was shown to be a primary response mediated through the activation of pre-existing transcription factors (63). In addition to the phosphorylation of the pre-existing c-Jun, the induction of AP-1 activity may occur at the transcriptional level (28). C-jun is expressed at all stages of osteoblastic differentiation (27) and mechanical stretch induces a transient increase in c-jun mRNA levels in hPDL cells (unpublished observations). It is not known whether the activated JNK2/ERK2 in the stretched hPDL cells would activate the de novo-synthesized c-Jun through the $\mathrm{N}$-terminal phosphorylations and, if they did, what its effect on the kinetics of AP-1-ALP promoter TRE complex formation would be. In this vein, we note that a dual input on the level of transcription and phosphorylation of c-Jun mediated by the combined action of JNK and ERK was proposed to signal a program of nerve growth factor (NGF)induced differentiation in PC12 cells (64).

Although the sequences around the c-Jun Nterminal phosphorylation sites are similar to those located in the trans-activation domain of c-Fos, a different protein kinase, FRK (Fos-regulating kinase; $\mathrm{M}_{\mathrm{r}}=88 \mathrm{kDa}$ ), phosphorylates this region and activates c-Fos in a Ras-dependent manner (65). FRK activation was not recorded in our sensitive in-gel kinase assay, corroborating the presumptive absence of c-Fos in the AP-1-ALP promoter TRE complexes (Fig. 4). On the other hand, C-terminal phosphorylation of c-Fos by ERK2 does not affect transactivation ability, but rather, increases the half-life of the protein (66). Since some of the Fos-responsive genes identified to date (e.g., osteocalcin) are expressed specifically in differentiating osteoblastic cells (67), it is possible that the observed short-lived capacity of ERK2 to enhance phosphorylation of cFos following mechanical stretching (Fig. 1) may serve to transiently stabilize the protein to execute a specific regulatory function during early gene reprograming in hPDL cells. Despite its small effect on cFos phosphorylation, ERK2 makes a very important contribution to the stimulation of AP-1 activity through phosphorylation of Elk-1/TCF, a transcription factor mediating c-fos induction (37). This would lead to an increase in the level of c-Fos available to form AP-1 heterodimers, thereby, modulating the spectrum of AP-1 partner interactions on osteoblast-specific promoter TREs (21-23). 
Obviously, MAPK signaling cascades are pivotal elements in the response of hPDL osteoblastic cells to mechanical stretch via the induction of distinct MAPK subtypes targeting the AP-1 transcription factor. The degree of cross-talk between these kinases and the integration of load-induced signaling inputs by both components of the AP-1 may allow mechanical stress conditions to determine the composition of the AP-1 complex and, thus, modulate osteoblast-restricted transcription at the promoter level. Chronological order or the duration of JNK/ERK activation, as well as the effects of weak versus strong activation also may be critical to cellular outcome (56). Precise kinetic analysis of each cascade, especially that of a very early time course after mechanical stimulation, is necessary to unravel temporal and hierarchical relationships of stretchinduced activation of early osteoblastic gene expression in hPDL cells. Although our understanding of these phenomena is rudimentary, it is clear that their dissection will be crucial to fully comprehend the signal transduction pathways of the mechanotranscription coupling process in the regulation of osteoblast reprograming and its contribution to the control of bone remodeling.

\section{Acknowledgments}

We are indebted to L. Staszewski for technical assistance at the early stages of the work and to D. Bohmann for valuable discussions. We would like to thank L. Huber for extensive review of this manuscript and Z. Lygerou for helpful suggestions. This study was supported in part by an EOS Research Grant (U.K.) to E.K. Basdra.

\section{References}

1. Lekic P, McCulloch CA. (1996) Periodontal ligament cell population: the central role of fibroblasts in creating a unique tissue. Anat. Res. 245: 327-341.

2. Arceo N, Sauk JJ, Moehring J, Foster RA, Somerman MJ. (1991) Human periodontal cells initiate mineral-like nodules in vitro. J. Periodontol. 62: 499-503.

3. Basdra EK, Papavassiliou AG, Huber LA. (1995) Rab and rho GTPases are involved in specific response of periodontal ligament fibroblasts to mechanical stretching. Biochim. Biophys. Acta 1268: 209-2 13.

4. Basdra EK, Komposch G. (1997) Osteoblast-like properties of human periodontal ligament cells: an in vitro analysis. Eur. J. Orthod. 19: 615-621.

5. Piche JE, Carnes DL Jr, Graves DT. (1989) Initial characterization of cells derived from human periodontia. J. Dent. Res. 68: 761-767.

6. Carnes DL, Maeder CL, Graves DT. (1997) Cells with osteoblastic phenotypes can be explanted from human gingiva and periodontal ligament. J. Periodontol. 68: 701-707.

7. Kletsas D, Basdra EK, Papavassiliou AG. (1998) Mechanical stress induces DNA synthesis in PDL fibroblasts by a mechanism unrelated to autocrine growth factor action. FEBS Lett. 430: 358-362.

8. Matsuda N, Yokoyama K, Takeshita S, Watanabe M. (1998) Role of epidermal growth factor and its receptor in mechanical stress-induced differentiation of human periodontal ligament cells in vitro. Arch. Oral Biol. 43: 987-997.
9. Egelberg J. (1987) Regeneration and repair of periodontal tissues. J. Periodont. Res. 22: 233-242.

10. Raab-Cullen DM, Akhter MP, Kimmel DB, Recker RR. (1994) Periosteal bone formation stimulated by externally induced bending strains. J. Bone Miner. Res. 9: 1143-1152.

11. Rubin CT, Gross TS, McLeod KJ, Bain SD. (1995) Morphologic stages in lamellar bone formation stimulated by a potent mechanical stimulus. J. Bone Miner. Res. 10: 488-495.

12. Shyy Y-J, Chien S. (1997) Role of integrins in cellular responses to mechanical stress and adhesion. Curr. Opin. Cell Biol. 9: 707-713.

13. Howe A, Aplin AE, Alahari SK, Juliano RL. (1998) Integrin signaling and cell growth control. Curr. Opin. Cell Biol. 10: 220-231.

14. Van Aelst L, D'Souza-Schorey D. (1997) Rho GTPases in signaling networks. Genes Dev. 11: 2295-2322.

15. Treisman R. (1996) Regulation of transcription by MAP kinase cascades. Curr. Opin. Cell Biol. 8: 205-215.

16. Robinson MJ, Cobb MH. (1997) Mitogen-activated protein kinase pathways. Curr. Opin. Cell Biol. 9: 180-186.

17. Davis RJ. (1994) MAPKs: new JNK expands the group. Trends Biochem. Sci. 19: 470-473.

18. Gupta S, Barrett T, Whitmarsh AJ, et al. (1996) Selective interaction of JNK protein kinase isoforms with transcription factors. $E M B O$ J. 15: 2760-2770.

19. Ip Y-T, Davis RJ. (1998) Signal transduction by the c-Jun Nterminal kinase (JNK) - from inflammation to development. Curr. Opin. Cell Biol. 10: 205-219.

20. Karin M, Hunter T. (1995) Transcriptional control by protein phosphorylation: signal transmission from the cell surface to the nucleus. Curr. Biol. 5: 747-757.

21. Rodan GA, Noda M. (1991) Gene expression in osteoblastic cells. Crit. Rev. Eukaryot. Gene Expr. 1: 85-98.

22. Stein GS, Lian JB, Stein JL, van Wijnen AJ, Montecino M. (1996) Transcriptional control of osteoblast growth and differentiation. Physiol. Rev. 76: 593-629.

23. Franceschi RT. (1999) The developmental control of osteoblastspecific gene expression: role of specific transcription factors and the extracellular matrix environment. Crit. Rev. Oral Biol. Med. 10: 40-57.

24. Karin M, Liu ZG, Zandi E. (1997) AP-1 function and regulation. Curr. Opin. Cell Biol. 9: 240-246.

25. Angel P, Baumann I, Stein B, Delius H, Rahmsdorf HJ, Herrlich P. (1987) 12-O-tetradecanoyl-phorbol-13-acetate induction of the human collagenase gene is mediated by an inducible enhancer element located in the $5^{\prime}$-flanking region. Mol. Cell. Biol. 7: 2256-2266.

26. Hai T, Curran T. (1991) Cross-family dimerization of transcription factors Fos/Jun and ATF/CREB alters DNA binding specificity. Proc. Natl. Acad. Sci. USA 88: 3720-3724.

27. McCabe LR, Kockx M, Lian J, Stein J, Stein G. (1995) Selective expression of fos- and jun-related genes during osteoblast proliferation and differentiation. Exp. Cell Res. 218: 255-262.

28. Karin M. (1995) The regulation of AP-l activity by mitogenactivated protein kinases. J. Biol. Chem. 270: 16483-16486.

29. Howard PS, Kucich U, Taliwal R, Korostoff JM. (1998) Mechanical forces alter extracellular matrix synthesis by human periodontal ligament cells. J. Periodontal Res. 33: 500-508.

30. Takeuchi Y, Suzawa M, Kikuchi T, Nishida E, Fujita T, Matsumoto T. (1997) Differentiation and transforming growth factor- $\beta$ receptor down-regulation by collagen- $\alpha 2 \beta 1$ integrin interaction is mediated by focal adhesion kinase and its downstream signals in murine osteoblastic cells. J. Biol. Chem. 272: 29309-29316.

31. Schmidt C, Pommerenke H, Dürr F, Nebe B, Rychly J. (1998) Mechanical stressing of integrin receptors induces enhanced tyrosine phosphorylation of cytoskeletally anchored proteins. J. Biol. Chem. 273: 5081-5085.

32. Komuro I, Kudo S, Yamazaki T, Zou Y, Shiojima I, Yazaki Y. (1996) Mechanical stretch activates the stress-activated protein kinases in cardiac myocytes. FASEB J. 10: 631-636.

33. Li Y-S, Shyy Y-J, Li S, et al. (1996) The Ras-JNK pathway is involved in shear-induced gene expression. Mol. Cell. Biol. 16: 5947-5954. 
34. Naruse K, Sokabe M. (1993) Involvement of stretch-activated ion channels in $\mathrm{Ca}^{2+}$ mobilization to mechanical stretch in endothelial cells. Am. J. Physiol. 264: C1037-C1044.

35. Papavassiliou AG, Treier M, Bohmann D. (1995) Intramolecular signal transduction in c-Jun. EMBO J. 14: 2014-2019.

36. Peverali FA, Isaksson A, Papavassiliou AG, et al. (1996) Phosphorylation of Drosophila Jun by the MAP kinase Rolled regulates photoreceptor differentiation. EMBO J. 15: 3943-3950.

37. Marais R, Wynne J, Treisman R. (1993) The SRF accessory protein Elk-1 contains a growth factor-regulated transcriptional activation domain. Cell 73: 381-393.

38. Weiss MJ, Ray K, Henthorn PS, Lamb B, Kadesch T, Harris H. (1988) Structure of the human liver/bone/kidney alkaline phosphatase gene. J. Biol. Chem. 263: 12002-12010.

39. Papavassiliou AG, Bohmann K, Bohmann D. (1992) Determining the effect of inducible protein phosphorylation on the DNA-binding activity of transcription factors. Anal. Biochem. 203: 302-309.

40. Whitmarsh AJ, Davis RJ. (1996) Transcription factor AP-1 regulation by mitogen-activated protein kinase signal transduction pathways. J. Mol. Med. 74: 589-607.

41. Dérijard B, Hibi M, Wu I, et al. (1994) JNK 1: a protein kinase stimulated by UV-light and Ha-Ras that binds and phosphorylates the c-Jun activation domain. Cell 76: 1025-1037.

42. Hibi M, Lin A, Smeal T, Minden A, Karin M. (1993) Identification of an oncoprotein- and UV-responsive protein kinase that binds and potentiates the c-Jun activation domain. Genes Dev. 7: 2135-2148.

43. Kyriakis JM, Banerjee P, Nikolakaki E, et al. (1994) The stress-activated protein kinase subfamily of c-Jun kinases. Nature 369: 156-160.

44. Binetruy B, Smeal T, Karin M. (1991) Ha-ras augments c-Jun activity and stimulates phosphorylation of its activation domain. Nature 351: 122-127.

45. Pulverer BJ, Kyriakis JM, Aruch J, Nikolakaki E, Woodgett JR. (1991) Phosphorylation of c-Jun mediated by MAP kinase. Nature 353: 670-674.

46. Smeal T, Binetruy B, Mercola DA, Birrer M, Karin M. (1991) Oncogenic and transcriptional cooperation with Ha-ras requires phosphorylation of c-Jun on serines 63 and 73. Nature 354: 494-496.

47. Devary Y, Gottlieb RA, Smeal T, Karin M. (1992) The mammalian ultraviolet response is triggered by activation of Src tyrosine kinases. Cell 71: 1081-1091.

48. Radler-Pohl A, Sachsenmaier C, Gebel S, et al. (1993) UVinduced activation of AP-1 involves obligatory extranuclear steps including Raf-1 kinase. EMBO J. 12: 1005- 1012.

49. Karin M. (1994) Signal transduction from the cell surface to the nucleus through the phosphorylation of transcription factors. Curr. Opin. Cell Biol. 6: 415-424.

50. Zernik J, Kream B, Twarog K. (1991) Tissue-specific and dexamethasone-inducible expression of alkaline phosphatase from alternative promoters of the rat bone/liver/kidney/ placenta gene. Biochem. Biophys. Res. Commun. 176: 1149- 1156.

51. Goseki M, Oida S, Takeda K, et al. (1995) Identification of bone-type alkaline phosphatase mRNA from human periodontal ligament cells. J. Dent. Res. 74: 319-322.
52. Henthorn PS, Millán JL, Leboy P. (1999) Acid and alkaline phosphatases. In: Seibel MJ, Robins SP, Bilezikian JP (eds.) Dynamics of Bone and Cartilage Metabolism. Academic Press, San Diego, CA, pp. 127-136.

53. Tuncay OC, Ho D, Barker MK. (1994) Oxygen tension regulates osteoblast function. Am. J. Orthod. Dentofac. Orthop. 105: 457-463.

54. Hipskind RA, Bilbe G. (1998) MAP kinase signaling cascades and gene expression in osteoblasts. Front. Biosci. 3: D804-D816.

55. Paul A, Wilson S, Belham CM, et al. (1997) Stress-activated protein kinases: activation, regulation and function. Cell Signal. 9: 403-410.

56. Marshall CJ. (1995) Specificity of receptor tyrosine kinase signaling: transient versus sustained extracellular signalregulated kinase activation. Cell 80: 179-185.

57. Hu Y, Böck G, Wick G, Xu Q. (1998) Activation of PDGF receptor in vascular smooth muscle cells by mechanical stress. FASEB J. 12: 1135-1142.

58. Galcheva-Gargova Z, Derijard B, Wu I-H, Davis RJ. (1994) An osmosensing signal transduction pathway in mammalian cells. Science 265: 806-808.

59. Minden A, Lin A, McMahon M, et al. (1994) Differential activation of ERK and JNK mitogen-activated protein kinases by Raf- 1 and MEKK. Science 266: 1719-1723.

60. Kockel L, Zeitlinger J, Staszewski LM, Mlodzik M, Bohmann D. (1997) Jun in Drosophila development: redundant and nonredundant functions and regulation by two MAPK signal transduction pathways. Genes Dev. 11: 1748-1758.

61. Shyy Y-J, Lin M-C, Han J, Lu Y, Petrime M, Chien S. (1995) The cis-acting phorbol ester 12-O-tetradecanoylphorbol 13acetate-responsive element is involved in shear-stressinduced monocyte chemotactic protein 1 gene expression. Proc. Natl. Acad. Sci. USA 92: 8069-8073.

62. Kuru L, Griffiths GS, Petrie A, Olsen I. (1999) Alkaline phosphatase activity is upregulated in regenerating human periodontal cells. J. Periodontal Res. 34: 123-127.

63. Toma CD, Ashkar S, Gray ML, Schaffer JL, Gerstenfeld LC. (1997) Signal transduction of mechanical stimuli is dependent on microfilament integrity: identification of osteopontin as a mechanically induced gene in osteoblasts. J. Bone Miner. Res. 12: 1626-1636.

64. Leppä S, Saffrich R, Ansorge W, Bohmann D. (1998) Differential regulation of C-Jun by ERK and JNK during PC12 cell differentiation. EMBO J. 17: 4404-4413.

65. Deng T, Karin M. (1994) c-Fos transcriptional activity stimulated by H-Ras-activated protein kinase distinct from JNK and ERK. Nature 371: 171-175.

66. Okazaki K, Sagata N. (1995) The Mos/MAP kinase pathway stabilizes c-Fos by phosphorylation and augments its transforming activity in NIH-3T3 cells. EMBO J. 14: 5048- 5059.

67. Grigoriadis AE, Wang Z-Q, Wagner EF. (1995) Fos and bone cell development: lessons from a nuclear oncogene. Trends Genet. 11: 436-441.

68. Quandt K, Frech K, Karas H, Wingender E, Werner T. (1995) MatInd and MatInspector - New fast and versatile tools for detection of consensus matches in nucleotide sequence data. Nucleic Acids Res. 23: 4878-4884. 